\title{
Alexithymia as a prognostic risk factor for health problems: a brief review of epidemiological studies
}

Masayo Kojima

\begin{abstract}
The number of articles on alexithymia has been steadily increasing since the word "alexithymia" was coined in the 1970s to denote a common characteristic that is observed among classic psychosomatic patients in whom therapy was unsuccessful. Alexithymia, a disorder of affect regulation, has been suggested to be broadly associated with various mental and physical health problems. However, most available evidence is based on anecdotal reports or cross-sectional observations. To clarify the predictive value of alexithymia for health problems, a systematic review of prospective studies was conducted. A search of the PubMed database identified 1,507 articles on "alexithymia" that were published by July 31, 2011. Among them, only 7 studies examined the developmental risks of alexithymia for health problems among nonclinical populations and 38 studies examined the prognostic value of alexithymia among clinical populations. Approximately half of the studies reported statistically significant adverse effects, while 5 studies demonstrated favorable effects of alexithymia on health outcomes; four of them were associated with surgical interventions and two involved cancer patients. The studies that showed insignificant results tended to have a small sample size. In conclusion, epidemiological evidence regarding alexithymia as a prognostic risk factor for health problems remains un-established. Even though alexithymia is considered to be an unfavorable characteristic for disease control and health promotion overall, some beneficial aspects are suggested. More prospective studies with sufficient sample sizes and follow-up period, especially those involving life course analyses, are needed to confirm the contribution of alexithymia to health problems.
\end{abstract}

Keywords: Systematic review, Prospective study, Epidemiology

\section{Introduction}

Alexithymia, a personality construct that reflects difficulties in affective self-regulation [1], was originally noted by psychotherapists as a common characteristic observed among classic psychosomatic patients in whom therapy was unsuccessful [2]. To date, researchers have revealed that alexithymia is broadly associated with various mental and physical health problems. It is now regarded as a key factor affecting treatment responses across the field of medical practice [3].

How is alexithymia associated with the development of health problems and their prognoses? Some of the

Correspondence: masayok@med.nagoya-cu.ac.jp

Department of Public Health, Nagoya City University Graduate School of Medical Sciences, 1 Kawasumi, Mizuho-cho, Mizuho-ku, Nagoya 467-8601, Japan

\section{Biomed Central

(c) 2012 Kojima; licensee BioMed Central Ltd. This is an Open Access article distributed under the terms of the Creative Commons Attribution License (http://creativecommons.org/licenses/by/2.0), which permits unrestricted use, distribution, and reproduction in any medium, provided the original work is properly cited. possible underlying mechanisms have been well documented in previous review articles $[1,4,5]$. First, alexithymic individuals have impaired emotion-processing and regulating capacities which might induce disruption of homeostasis through alterations of autonomic, endocrine, and immune activities [1]. Second, alexithymic patients have a limited ability to cope adaptively with stressful situations and tend to have unhealthy behaviors, such as poor nutrition, alcohol and drug use, and a sedentary lifestyle $[4,5]$. Third, alexithymic patients have difficulties in recognizing their own physical and emotional symptoms, which may be linked to a delay or excessive use of medical support, resulting in a poor prognosis. Finally, because of their difficulties communicating their own inner feelings and a poor understanding of other people's emotions, alexithymic patients find it 
difficult to build and maintain close relationships with others and to appropriately utilize social supports in order to protect themselves from the potentially pathological influences of stressful events [6].

Thus, theoretically, there is no doubt that alexithymia plays a key role in disease control and health promotion.

\section{Review of prospective cohort studies on alexithymia}

Prospective cohort studies are the best type of observational design applied to examine the etiology and prognosis of health problems [7]. Since Sifneos introduced the concept of alexithymia in 1973 [2], the number of articles regarding alexithymia has been increasing year by year. According to the review by Taylor and Bagby published in 2004 [8], a search of the PsycINFO database revealed more than 1,000 journal articles on alexithymia, while approximately 120 publications on alexithymia had appeared by the mid-80s. However, most of them were anecdotal or cross-sectional data reports. To update the evidence and clarify the predictive value of alexithymia as a health determinant, a brief systematic review of the epidemiological literature was conducted.

\section{Method of systematic review}

The minimum criteria for studies to be included in the current review were as follows: (1) a prospective design with a clinical or nonclinical population sample, (2) evaluating the effects of baseline alexithymia on healthrelated outcomes, (3) using validated methods to assess alexithymia, and (4) written in English. To capture the broad linkage between alexithymia and health outcomes, the types of treatments and outcomes were not specified in the process of data collection. $P \leq 0.05$ was considered statistically significant.

A systematic search was conducted using the PubMed database limiting the period from January 1, 1975 to July 31, 2011. A total of 1,507 documents were identified using ["alexithymia" or "alexithymic"] as search terms. By further adding ["prospective" or "prognostic" or "cohort" or "follow"] to the search terms, the search yielded 193 titles. After excluding 19 articles that were written in non-English languages and 8 articles that were published as a review, the remaining 166 articles were inspected manually. Among them, only 7 articles were identified as those reporting the developmental risks of alexithymia for health problems among nonclinical populations, and 38 articles were identified as those reporting the influences of alexithymia on prognosis or results of interventions among hospital-based populations. The reason for exclusion of most studies was the cross-sectional design of data collection $(n=106)$. Fifteen studies were excluded even though they were prospectively designed because they treated alexithymia as an outcome. Three articles were excluded because they were editorials or commentaries.

Almost all studies included in the current review used the Toronto Alexithymia Scale (TAS) or TAS-20 $[9,10]$ as a tool for evaluating alexithymia. Only two studies used other tools; one study used the Beth Israel Questionnaire and Schalling-Sifneos Personality Scale [11], and the other study used projective personality tests $[12,13]$; they were included in the current review.

\section{Major findings from nonclinical population studies}

Table 1 shows the summary of studies examining the effects of alexithymia on health outcomes with a prospective design in a nonclinical population. Seven studies prospectively examined the developmental risks of alexithymia for health problems among nonclinical populations [14-20]. Among them, 3 studies demonstrated the statistically significant adverse risk of baseline alexithymia for subsequent health problems [14-16], 3 studies reported no association [18-20], and one reported the beneficial effect of alexithymia on health [17].

Two studies were based on the same large cohort data derived from the Finnish general male population and demonstrated the statistically significant adverse effects of alexithymia on total mortality and/or cardiac death $[14,15]$. A recently conducted cross-sectional study has reported results which may support the findings of these studies. Grabe et al examined 1,168 subjects who were randomly selected from the general population and found a significant association of alexithymia with hypertension and atherosclerotic plaques [21]. The authors pointed out that alexithymia may serve as a long-standing risk factor as well as a familial and genetic factor that deregulates the autonomic nervous system [21]. Autonomic nervous deregulation may positively influence the developmental risk for cardiac death and total mortality.

The most recently published Finnish report failed to show a significant association between baseline alexithymia and subsequent psychiatric diagnoses, such as major depression, personality disorder, and alcohol use disorders, which were confirmed by a structured clinical interview [18]. However, the report is based on the subsample data $(\mathrm{n}=290)$ selected from a general population cohort $(n=2,050)$ by the presence or absence of chronic high mental symptoms. The study subjects were limited to those who completed the successive 3-year follow-up surveys (1998, 1999, and 2001) and a 7-year follow-up survey including a structured interview (2005). It cannot be denied that a considerable number of alexithymic participants might have developed mental disorders before 2005 and quit the study, which may have caused underestimation of the impact of alexithymia. In 


\begin{tabular}{|c|c|c|c|c|c|c|c|}
\hline $\begin{array}{l}\text { Effects of } \\
\text { alexithymia }\end{array}$ & $\mathbf{N}$ & Population & $\begin{array}{l}\text { Follow up } \\
\text { period }\end{array}$ & Outcomes & Country & $\begin{array}{l}\text { Published } \\
\text { year }\end{array}$ & $\begin{array}{l}\text { Reference } \\
\text { no }\end{array}$ \\
\hline Adverse & 2321 & General population & 20 years & Cardiac death & Finland & 2010 & 14 \\
\hline Adverse & 2297 & General population & 5.5 years & All cause morality & Finland & 1996 & 15 \\
\hline Adverse & 54 & Police officer & 2 years & PTSD & USA & 2006 & 16 \\
\hline Beneficial & 1207 & Urban public transit Operators & 7.5 years & Low back pain & USA & 2007 & 17 \\
\hline No association & 333 & $\begin{array}{l}\text { Subsample selected from general population } \\
\text { cohort study sample }\end{array}$ & 7 years & Depression & Finland & 2010 & 18 \\
\hline No association & 154 & General population & $30-22$ years & $\begin{array}{l}\text { Neck-shoulder and } \\
\text { low-back pain }\end{array}$ & Finland & 1991 & 19 \\
\hline No association & 43 & Fire fighter & 2 years & PTSD & Switzerland & 2005 & 20 \\
\hline
\end{tabular}

addition, the authors included previous depressive symptoms (BDI sum score) in logistic regression analysis to estimate the developmental risk of depression and that might have caused over adjustment [22]. In fact, the results of simple Chi square tests suggested significantly higher prevalence of such psychiatric diagnoses among those who had a TAS-20 sum score above the median [18].

Two studies examined the predictive value of alexithymia on the development of low-back pain (LBP) $[17,19]$. One study found no association between baseline alexithymia that was evaluated by projective personality tests and the reported severity of neck-shoulder pain and/or LBP among 154 subjects, randomly selected from the general population [19]. The other study examined 1,207 municipal bus drivers and found a favorable association between alexithymia and the 7.5-year incidence of compensated LBP [17]. Inversely, the same research group reported an adverse association between alexithymia and LBP claims from cross-sectional data derived from the same population [23]. The authors speculated that the prevalence of self-reported LBP symptoms and the incidence of compensated LBP claims are not comparable even within the same population, and it might be difficult for alexithymic patients to complete the bureaucratic process to receive compensation, resulting in the low prevalence of compensated LBP [17].

Two studies examined the developmental risks of alexithymia for post-traumatic stress disorder (PTSD) and the results were inconsistent $[16,20]$. One study examined 43 male firefighters for 2 years and found no significant risk of alexithymia [20]. The other study examined 54 police officers and reported that their TAS20 scores significantly predicted PTSD symptoms for 2 years [16]. Both studies have too small sample size to estimate the developmental risk of PTSD associated with alexithymia. Further studies with sufficient sample size and follow-up period are necessary to confirm the vulnerability of alexithymic individuals to PTSD.

\section{Major findings from clinical population studies}

A summary of studies examining the effect of alexithymia on health outcomes with a prospective design in a clinical population is shown in Table 2 . In total, 38 articles were identified that reported the clinical impacts of alexithymia on prognosis [24-61]. Major types of participants were patients with psychiatric or psychosomatic illness recruited consecutively and the main outcome was the treatment response. Most of them were preliminary, naturalistic studies without control groups. Some studies assigned subjects to a specific treatment or other intervention, but none reported the blinding procedure. Overall, information to evaluate the risk of bias of each study is very limited; therefore, the presence of serious risk of bias should be considered to interpret the results.

The number of studies reporting the adverse effects of alexithymia was 18 [24-41], which was approximately $50 \%$ of the total studies. Five studies demonstrated the beneficial effects of alexithymia on clinical outcomes [42-46]. One-third of the identified clinical studies $(n=15)$ reported no statistically significant associations between baseline alexithymia and treatment outcomes [47-61]. The studies that failed to find significant associations between alexithymia and clinical outcomes tended to have small sample sizes (median $=54, \min =19$, $\max =297$ ) [47-61] compared with those that demonstrated significant results (median $=103, \mathrm{~min}=30$, $\max =480)$ [24-46].

The influence of alexithymia on the treatment process and outcomes has been discussed intensively by Lumley et al $[4,5]$. They speculated that alexithymic patients might respond poorly to psychological treatments, although perhaps not to cognitive behavioral techniques because the compulsive nature and external focus of people with alexithymia may prompt greater adherence to structured exercises and behavioral recommendations [4]. The current review does not identify clear differences by the types of therapy in the influences of alexithymia on the outcomes. However, relatively consistent 
Table 2 Studies examining the effects of alexithymia on health outcomes with a prospective cohort design in clinicalpopulation

\begin{tabular}{|c|c|c|c|c|c|c|}
\hline Type of participants & $\begin{array}{l}\text { Follow up } \\
\text { period }\end{array}$ & Type of treatment & Type of main outcome & $\mathbf{N}$ & Country & $\begin{array}{l}\text { Ref. } \\
\text { no. }\end{array}$ \\
\hline \multicolumn{7}{|l|}{ Adverse effect } \\
\hline Psychiatric inPT & $4,8-12 W$ & Multimodal psychotherapy & $\begin{array}{l}\text { Global severity Index and } \\
\text { depression severity }\end{array}$ & 480 & Germany & 24 \\
\hline Substance users & $10+15 W$ & Motivational intervention & Response to treatment & 260 & USA & 25 \\
\hline Psychiatric outPT & $12-21 \mathrm{~W}$ & Short-term psychotherapy & Psychiatric symptomatology & 251 & Canada & 26 \\
\hline Hemodialysis outPT & $5 Y$ & Hemodialysis therapy & All cause mortality & 230 & Japan & 27 \\
\hline Hemodialysis outPT & $6 \mathrm{M}$ & Hemodialysis therapy & Depression deterioration & 230 & Japan & 28 \\
\hline OutPT with possible & $6 Y$ & Pyschotherapy & Recovery from depression & 121 & Finland & 29 \\
\hline $\begin{array}{l}\text { Veterans with military sexual } \\
\text { trauma. }\end{array}$ & $7 \mathrm{~W}$ & Specialized residential treatment & Symptom persistence & 175 & USA & 30 \\
\hline $\begin{array}{l}\text { Women taking elective surgical } \\
\text { abortion }\end{array}$ & $2 \mathrm{M}$ & Surgical abortion & Re-experience and avoidance & 140 & Netherlands & 31 \\
\hline $\begin{array}{l}\text { OutPT with functional } \\
\text { gastrointestinal disorders }\end{array}$ & $6 \mathrm{M}$ & Unspecified treatment & Response to treatment & 112 & Italy & 32 \\
\hline $\begin{array}{l}\text { PT taking implantable cardioverter } \\
\text { defibrillator }\end{array}$ & $2-5.5 Y$ & ICD placement & Posttraumatic stress & 107 & Switzerland & 33 \\
\hline Eating disorder PT & $3 Y$ & $\begin{array}{l}\text { Drug treatment and } \\
\text { psychotherapy }\end{array}$ & $\begin{array}{l}\mathrm{PT}^{\prime} \text { compliance and types of } \\
\text { treatments }\end{array}$ & 102 & France & 34 \\
\hline Eating disorder PT & $3 Y$ & Unspecified treatment & Response to treatment & 102 & France & 35 \\
\hline OutPT with major depression & $1 Y$ & Unspecified treatment & Response to treatment & 86 & Finland & 36 \\
\hline PT with asthma & $2 Y$ & Unspecified treatment & $\begin{array}{l}\text { Emargency room visits and QOL } \\
\text { (SF-36) }\end{array}$ & 76 & Spain & 37 \\
\hline OutPT with major depression & $10 \mathrm{~W}$ & Antidepressant & Reduction of depression severity & 65 & Turkey & 38 \\
\hline PT with type 1 Diabetes & $8 W$ & Inpatient treatment & Decrease in $\mathrm{HbA} 1 \mathrm{c}$ & 64 & Belgium & 39 \\
\hline Alcohol abuser & $15 \mathrm{~W}$ & Inpatient treatment & Maintaining abstinent & 46 & France & 40 \\
\hline $\begin{array}{l}\text { PT with somatoform and anxiety } \\
\text { disorder }\end{array}$ & $2 Y$ & Inpatient treatment & Symptom persistence & 30 & Austria & 41 \\
\hline \multicolumn{7}{|l|}{ Beneficial effect } \\
\hline Cancer PT & $6 \mathrm{M}$ & $\begin{array}{l}\text { Multicomponent psychological } \\
\text { intervention }\end{array}$ & Pain & 104 & Italy & 42 \\
\hline PT taking in vitro fertilization & $6 \mathrm{M}$ & In vitro fertilization & Delivery of a living infant & 81 & Greece & 43 \\
\hline Colorectal cancer PT & $3 Y$ & Surgery & QOL (SF-36) & 60 & Italy & 44 \\
\hline Ulcerative colotis PT & $17 \mathrm{M}$ & Pelvic pouch surgery & Psychosocial adjustment & 53 & Sweden & 45 \\
\hline Gynecologic PT & $1 \mathrm{M}$ & Laparoscopy or laparotomy & QOL (SF-36) & 40 & Italy & 46 \\
\hline \multicolumn{7}{|l|}{ No association } \\
\hline Psychiatric inPT & $4,8-12 W$ & Psychodynamic group therapy & $\begin{array}{l}\text { Global severity Index and } \\
\text { depression severity }\end{array}$ & 297 & Germany & 47 \\
\hline $\begin{array}{l}\text { OutPT with unexplained physical } \\
\text { symptom }\end{array}$ & $6 \mathrm{~W}$ & Unspecified treatment & Symptom persistence & 127 & Netherland & 48 \\
\hline Pregnant women & $1 \mathrm{M}$ & Unspecified & Depression development & 149 & Italy & 49 \\
\hline PT with psoriasis & $6 \mathrm{M}$ & Cognitive behavioral therapy & Response to treatment & 80 & UK & 50 \\
\hline Obese outPT & $8 \mathrm{M}$ & Behavioral program & Compliance and weight loss & 68 & Italy & 51 \\
\hline $\begin{array}{l}\text { InPT taking respiratory } \\
\text { rehabilitation }\end{array}$ & $4 \mathrm{~W}$ & Respiratory rehabilitation & Functional recovery & 60 & Italy & 52 \\
\hline Panic disorder PT & $6 \mathrm{M}$ & CBT & Response to treatment & 55 & Switzerland & 53 \\
\hline Psychiatric consultation outPT & $1 Y$ & Psychotherapy & PT's compliance & 54 & Finland & 54 \\
\hline OCD inPT & 31-139 D & Multimodal CBT & Response to treatment & 42 & Germany & 55 \\
\hline
\end{tabular}




\begin{tabular}{|c|c|c|c|c|c|c|}
\hline Bulmia nervosa PT & $10 \mathrm{~W}$ & Drug treatment & Symptom improvements & 41 & England & 56 \\
\hline CFS outPT & $18 \mathrm{M}$ & Unspecified treatment & Symptom improvements & 40 & Netherland & 57 \\
\hline OutPT with psoriasis & $3 \mathrm{M}$ & Delmatological treatment & Response to treatment & 40 & France & 58 \\
\hline OCD inPT & $6 Y$ & Inpatient treatment & OCD deteriotion & 34 & Switzerland & 59 \\
\hline Schizophrenia outPT & $1 Y$ & Appropriate treatment & Symptom improvements & 29 & Italy & 60 \\
\hline Eating disorder inPT & $1 Y$ & Psychoeducation & Dietary restraint & 19 & Switzerland & 61 \\
\hline
\end{tabular}

$\mathrm{PT}=$ patient, $\mathrm{OCD}=$ obsessive-compulsive disorders, $\mathrm{CFS}=$ chronic fatigue syndrome, $C B T=$ cognitive behavioral therapy, $\mathrm{W}=$ week, $\mathrm{M}=\mathrm{month}, \mathrm{Y}=\mathrm{year}$.

beneficial effects of alexithymia were observed in studies with surgical interventions [43-47].

To date, the association between surgical treatments and alexithymia has rarely been discussed. Kakatsaki et al examined 81 women undergoing an in vitro fertilization program during a 6 month period and found that alexithymia predicted better outcome; delivery of a living infant [43]. Ripetti et al examined a series of 60 colorectal cancer patients with a three-month follow-up and found that a highlevel alexithymia group (TAS-20 $\geq 51$ ) showed more improvement in QOL measured by SF-36 test after surgery than did the low-level alexithymia group [44]. Weinryb et al examined 53 consecutive patients undergoing pelvic pouch surgery and followed them for 16 to 41 months [45]. They found that the level of alexithymia measured by the Beth Israel Questionnaire was inversely correlated with worse psychological distress and adjustment in relationships at home after surgery. Battista et al examined 40 consecutive patients with benign gynecologic pathology who underwent laparoscopy or laparotomy and found that patients with low-level of alexithymia (TAS-20 $\leq$ 59) showed a worsening of QOL score measured by SF-36 after a surgical procedure [46]. In general, surgical treatment procedures are highly structured and active so that the externally oriented thinking style of alexithymic patients may suit them well. Ripetti et al speculated that patients with alexithymia might perceive invasive surgery to be effective because surgical treatment leaves a visible body sign [44]. Weinryb et al suggested that patients with alexithymia may tend to have avoidant coping strategies to the negative aspects of surgery such that they may have better recovery during the postoperative period [45]. On the contrary, a study investigating short term re-experiencing and avoidance after surgical abortion conducted by van Emmerik et al demonstrated a significant adverse effect of alexithymia on the outcomes [31]. Because of the variety of the study backgrounds and the types of treatments and outcomes, we cannot draw definite conclusions from the available data. Further research will be necessary to fully disclose the favorable aspects of alexithymia on treatment outcomes.

One prospective study involving cancer patients conducted by Tulipani showed a significant beneficial effect of alexithymia on reduction in pain perception by psychological intervention to cancer patients [42]. They recruited study participants consecutively, and randomly allocated them to an intervention group or a control group. A total of 52 cancer patients were provided the 6-month psychological intervention with a variety of therapeutic approaches according to guidelines issued in the literature on alexithymia and cancer pain and compared to 52 controls. Psychological intervention significantly reduced alexithymia as well as pain. Multiple regression analysis showed that baseline alexithymia and psychological intervention were both independently associated with a reduction in pain perception. The role of alexithymia in cancer patients is still under study [62]. The effectiveness of intervention focusing on the reduction of alexithymia to improve QOL should be examined among cancer patients and other populations in future research.

Most studies examined the associations between baseline alexithymia and treatment outcomes, whereas only one study reported the 5-year total mortality risk of alexithymia [27]. Interestingly, the increased risk of total mortality associated with alexithymia in hemodialysis patients (multivariate adjusted hazard ratio $=3.62$; 95\% CI: 1.32-9.93) was higher than that observed among Finnish middle-aged men (1.96; 1.31-2.94) [15]. Whether or not the impact of alexithymia on total mortality may differ by populations should be further investigated.

Issues for future epidemiological research on alexithymia Although alexithymia has been considered an unfavorable personality dimension for health promotion and disease prevention, the results of epidemiological studies were inconsistent. Most of them are preliminary and have many methodological problems. Apparently, we need more systematic, prospective studies with sound design to verify each pathway explaining the relationship between alexithymia and health problems that have been 
theoretically suggested [5]. There are some important points to be followed when conducting an epidemiological study to clarify the influence of alexithymia on health. First, alexithymia is considered a relatively stable characteristic, but it is actually dependent on psychological and/or physical conditions. Therefore, alexithymia should be chronologically measured repeatedly in the same individuals. Second, alexithymia and negative affect are closely associated. Also, interactions with social support cannot be dismissed when examining the influence of alexithymia on health problems. Thus, social support as well as negative affect must be assessed simultaneously when evaluating alexithymia to exclude potential confounding in statistical analysis. Third, if the pre-test score is extremely high, it is likely to show a drop in the post-test score; "regression to the mean [63]." People with alexithymia tend to have higher scores of distress than people without alexithymia. Therefore, simple subtraction of the post-treatment score from the pre-treatment score may cause overestimation of the treatment effect. Using the residual gain score, which is the difference between the actual post-test score and the score that was predicted from a regression equation is one method to adjust the phenomenon, and the use of the analyses of covariance method is also recommended [63]. Finally, as suggested by Grabe et al, alexithymia is considered to be a long-standing risk factor as well as a familial and genetic factor of health [21]. To detect the association between alexithymia and the developmental risk of specific health problems, a long observational period is required. Especially, the association between alexithymia and the onset of depression may occur at a relatively early stage of life. If so, prospective study of the middle-aged population may omit persons who have already developed depression due to alexithymia and overlook the association between them.

\section{Alexithymia might explain social health inequality}

Marmot, who directed the Whitehall Study, a longitudinal epidemiological study of British civil servants, pointed out from his 30 years of research that there are great health inequalities throughout the world that are related to social hierarchy [64-66]. According to Marmot's speculations, what profoundly affects our health and longevity is not income or lifestyle but autonomy and the opportunities for complete social participation; these follow social gradients and result in health inequalities [66]. Externally oriented thinking styles may inhibit alexithymic patients from feeling like they are in control, and their difficulty in 'identifying and describing ones' own inner feelings" may make them reluctant to participate in social activities. To date, there are two published studies reporting the association between alexithymia and long-term total mortality [15,27], and both of them supported the above hypothesis. Considering its construct, alexithymia might be a key health determinant, as Marmot suggested [65]. In order to resolve social inequalities and improve our health, we should approach the structure of the whole society to reduce alexithymia urgently. Recently, several researchers reported successful interventions to reduce the level of alexithymia $[42,51,67,68]$. We need more evidence to establish the treatment strategy for alexithymia.

\section{How to approach alexithymia}

The etiology of alexithymia has not been completely determined. Recent studies revealed the contribution of genetic factors to alexithymia development [69-74]. Several studies suggested that the social environment of early life and cultural factors influence alexithymia development [75-77]. Alexithymia is also known to develop secondarily as a reaction to stressful situations [78]. Moreover, some constructs may overlap with alexithymia $[4,79]$, such as emotional intelligence, emotional awareness, empathy deficits $[80,81]$, and autism spectrum disorders [82,83]. How a person develops alexithymic characteristics and how it affects his or her health throughout the life course need to be clarified. We also need to know how to approach alexithymic patients when their developmental backgrounds are varied.

Current review has revealed some favorable influences of alexithymia on surgical treatment outcomes [42-46]. A positive influence of alexithymia on behavioral treatments and adherence to treatment recommendations has been observed in several previous studies [4]. Lumley et al speculated that the compulsive nature and external focus of alexithymic patients prompt greater adherence to structured exercises and behavioral recommendations [4]. If clinicians and family members understand the characteristics of alexithymic patients and provide them with appropriate support, they might exhibit good compliance and thereby achieve good health outcomes. This point should be further explored in future studies.

\section{Study limitation}

To conduct the current systematic review, only the PubMed database for a limited period was used for the article search. The results of unpublished studies or articles not registered for PubMed were not included. Therefore, this systematic review did not cover all existing studies regarding alexithymia and the data need to be updated.

Almost all epidemiological studies reviewed in this article used the TAS or its short version, the TAS-20, to evaluate alexithymia. Both of them are self-measure questionnaires and have been used widely because of their good reliability and feasibility [84]. However, it has 
been argued that people with severe alexithymia may not evaluate their symptoms correctly because of having difficulty perceiving their inner feelings [85]. Moreover, a significant positive correlation of the TAS or the TAS-20 score and negative affect has been reported consistently [84]. The original authors of the TAS have recommended the measurement of alexithymia with several tools using different methods [8]. Whether or not we should use multiple measures of alexithymia has been very well discussed in the review article by Lumley et al [4]. Even though the application of interview-based assessment to epidemiological studies with large samples is difficult, the differences in measuring tools, especially those that include objective measures, should be verified in the future.

\section{Conclusions}

The epidemiological evidence regarding alexithymia as a prognostic risk factor for health problems is insufficient. Prospective studies with sufficient sample sizes will be necessary in order to confirm the contribution of alexithymia to health problems.

\section{Competing interests}

The author declares that she has no competing interests.

\section{Acknowledgements}

This study was supported by a Grant-in Aid for JSPS KAKENHI 21590708.

Received: 5 March 2012 Accepted: 13 December 2012

Published: 17 December 2012

\section{References}

1. Taylor GJ, Bagby RM, Parker JDA: Disorders of affect regulation. Cambridge: Cambridge University Press; 1997

2. Sifneos PE: Problems of psychotherapy of patients with alexithymic characteristics and physical disease. Psychother Psychosom 1975, 26:65-70.

3. Fassino S: Psychosomatic approach is the new medicine tailored for patient personality with a focus on ethics, economy, and quality. Panminerva Med 2010, 52:249-264.

4. Lumley MA, Neely LC, Burger AJ: The assessment of alexithymia in medical settings: implications for understanding and treating health problems. J Pers Assess 2007, 89:230-246.

5. Lumley MA, Stettner L, Wehmer F: How are alexithymia and physical illness linked? a review and critique of pathways. J Psychosom Res 1996, 41:505-518.

6. Kojima M, Senda Y, Nagaya T, Tokudome S, Furukawa TA: Alexithymia, depression and social support among Japanese workers. Psychother Psychosom 2003, 72:307-14.

7. Hemingway H, Marmot M: Evidence based cardiology: psychosocial factors in the aetiology and prognosis of coronary heart disease. Systematic review of prospective cohort studies. BMJ 1999, 318:14601467.

8. Taylor GJ, Bagby RM: New trends in alexithymia research. Psychother Psychosom 2004, 73:68-77.

9. Bagby RM, Parker JD, Taylor GJ: The twenty-item Toronto alexithymia scale-I. Item selection and cross- validation of the factor structure. J Psychosom Res 1994, 38:23-32.

10. Bagby RM, Taylor GJ, Parker JD: The twenty-item Toronto alexithymia scale-Il. Convergent, discriminant, and concurrent validity. J Psychosom Res 1994, 38:33-40.

11. Apfel RJ, Sifneos PE: Alexithymia: concept and measurement. Psychother Psychosom 1979, 32:180-190.
12. Murray HA: Thematic appreciation test; manual. Cambridge: Massachusetts Harvard University Press; 1943.

13. Andrew G, Hartwell SW, Hutt ML, Walton RE: The Michigan picture test. Chicago: Science Research Associate; 1953.

14. Tolmunen T, Lehto SM, Heliste M, Kurl S, Kauhanen J: Alexithymia is associated with increased cardiovascular mortality in middle-aged Finnish men. Psychosom Med 2010, 72:187-191.

15. Kauhanen J, Kaplan GA, Cohen RD, Julkunen J, Salonen JT: Alexithymia and risk of death in middle-aged men. J Psychosom Res 1996, 41:541-549.

16. McCaslin SE, Metzler TJ, Best SR, Liberman A, Weiss DS, Fagan J, Marmar CR: Alexithymia and PTSD symptoms in urban police officers: cross-sectional and prospective findings. J Trauma Stress 2006, 19:361-373.

17. Mehling WE, Krause N: Alexithymia and 7.5-year incidence of compensated low back pain in 1207 urban public transit operators. J Psychosom Res 2007, 62:667-674.

18. Honkalampi K, Hintikka J, Koivumaa-Honkanen H, Antikainen R, Haatainen K, Viinamaki $\mathrm{H}$ : Long-term alexithymic features indicate poor recovery from depression and psychopathology. A six-year follow-up. Psychother Psychosom 2007, 76:312-314.

19. Viikari-Juntura E, Vuori J, Silverstein BA, Kalimo R, Kuosma E, Videman T: A life-long prospective study on the role of psychosocial factors in neckshoulder and low-back pain. Spine (Phila Pa 1976) 1991, 16:1056-1061.

20. Heinrichs M, Wagner D, Schoch W, Soravia LM, Hellhammer DH, Ehlert U: Predicting posttraumatic stress symptoms from pretraumatic risk factors: a 2-year prospective follow-up study in firefighters. Am J Psychiatry 2005, 162:2276-2286.

21. Grabe HJ, Schwahn C, Barnow S, Spitzer C, John U, Freyberger HJ, Schminke $U$, Felix S, Völzke H: Alexithymia, hypertension, and subclinical atherosclerosis in the general population. J Psychosom Res 2010, 68:139-47.

22. Schisterman EF, Cole SR, Platt RW: Overadjustment bias and unnecessary adjustment in epidemiologic studies. Epidemiology 2009, 20:488-95.

23. Mehling WE, Krause N: Are difficulties perceiving and expressing emotions associated with low-back pain? The relationship between lack of emotional awareness (alexithymia) and 12-month prevalence of low-back pain in 1180 urban public transit operators. J Psychosom Res 2005, 58:73-81.

24. Leweke F, Bausch S, Leichsenring F, Walter B, Stingl M: Alexithymia as a predictor of outcome of psychodynamically oriented inpatient treatment. Psychother Res 2009, 19:323-331.

25. Rosenblum A, Foote J, Cleland C, Magura S, Mahmood D, Kosanke N: Moderators of effects of motivational enhancements to cognitive behavioral therapy. Am J Drug Alcohol Abuse 2005, 31:35-58.

26. McCallum M, Piper WE, Ogrodniczuk JS, Joyce AS: Relationships among psychological mindedness, alexithymia and outcome in four forms of short-term psychotherapy. Psychol Psychother 2003, 76:133-144.

27. Kojima M, Hayano J, Suzuki S, Seno H, Kasuga H, Takahashi H, Toriyama T, Kawahara H, Furukawa TA: Depression, alexithymia and long-term mortality in chronic hemodialysis patients. Psychother Psychosom 2010, 79:303-311.

28. Kojima M, Hayano J, Tokudome S, Suzuki S, Ibuki K, Tomizawa H, Nakata A, Seno $H$, Toriyama T, Kawahara $H$, et al: Independent associations of alexithymia and social support with depression in hemodialysis patients. J Psychosom Res 2007, 63:349-356.

29. Honkalampi K, Koivumaa-Honkanen H, Lehto SM, Hintikka J, Haatainen K, Rissanen T, Viinamaki $\mathrm{H}$ : Is alexithymia a risk factor for major depression, personality disorder, or alcohol use disorders? a prospective populationbased study. J Psychosom Res 2010, 68:269-273.

30. O'Brien C, Gaher RM, Pope C, Smiley P: Difficulty identifying feelings predicts the persistence of trauma symptoms in a sample of veterans who experienced military sexual trauma. J Nerv Ment Dis 2008, 196:252-255.

31. van Emmerik AA, Kamphuis JH, Emmelkamp PM: Prevalence and prediction of re-experiencing and avoidance after elective surgical abortion: a prospective study. Clin Psychol Psychother 2008, 15:378-385.

32. Porcelli P, Bagby RM, Taylor GJ, De CM, Leandro G, Todarello O: Alexithymia as predictor of treatment outcome in patients with functional gastrointestinal disorders. Psychosom Med 2003, 65:911-918.

33. Von KR, Baumert J, Kolb C, Cho EY, Ladwig KH: Chronic posttraumatic stress and its predictors in patients living with an implantable cardioverter defibrillator. J Affect Disord 2011, 131:344-352. 
34. Speranza M, Loas G, Guilbaud O, Corcos M: Are treatment options related to alexithymia in eating disorders? Biomed Pharmacother: Results from a threeyear naturalistic longitudinal study; 2010

35. Speranza M, Loas G, Wallier J, Corcos M: Predictive value of alexithymia in patients with eating disorders: a 3-year prospective study. J Psychosom Res 2007, 63:365-371.

36. Viinamaki H, Hintikka J, Tanskanen A, Honkalampi K, Antikainen R, Koivumaa-Honkanen $\mathrm{H}$, Haatainen $\mathrm{K}$, Saarinen $\mathrm{P}$, Lehtonen J: Partial remission in major depression: a two-phase, 12-month prospective study. Nord J Psychiatry 2002, 56:33-37.

37. Vazquez I, Sandez E, Gonzalez-Freire B, Romero-Frais E, Blanco-Aparicio M, Verea-Hernando $\mathrm{H}$ : The role of alexithymia in quality of life and health care use in asthma. J Asthma 2010, 47:797-804.

38. Ozsahin A, Uzun O, Cansever A, Gulcat Z: The effect of alexithymic features on response to antidepressant medication in patients with major depression. Depress Anxiety 2003, 18:62-66.

39. Luminet $\mathrm{O}$, De TP, Buysschaert M, Luts $\mathrm{A}$ : The role of alexithymia factors in glucose control of persons with type 1 diabetes: a pilot study. Diabetes Metab 2006, 32:417-424.

40. Loas G, Fremaux D, Otmani O, Lecercle C, Delahousse J: Is alexithymia a negative factor for maintaining abstinence? A follow-up study. Compr Psychiatry 1997, 38:296-299.

41. Bach M, Bach D: Predictive value of alexithymia: a prospective study in somatizing patients. Psychother Psychosom 1995, 64:43-48.

42. Tulipani C, Morelli F, Spedicato MR, Maiello E, Todarello O, Porcelli P. Alexithymia and cancer pain: the effect of psychological intervention. Psychother Psychosom 2010, 79:156-163.

43. Kakatsaki D, Vaslamatzis G, Chatziandreou M, Anastasiadi K, Dafni U, Tzavara C, Stefanidis K, Loutradis D, Antsaklis A: Alexithymia is positively associated with the outcome of in vitro fertilization (IVF) treatment Psychol Rep 2009, 105:522-532.

44. Ripetti V, Ausania F, Bruni R, Campoli G, Coppola R: Quality of life following colorectal cancer surgery: the role of alexithymia. Eur Surg Res 2008, 41:324-330.

45. Weinryb RM, Gustavsson JP, Barber JP: Personality predictors of dimensions of psychosocial adjustment after surgery. Psychosom Med 1997, 59:626-631.

46. Battista C, Angioli R, Cafa EV, Sereni MI, Vulcano E, Bruni R: Alexithymia-a disorder of the regulatory mechanism of the emotion elaboration-and quality of life in gynecologic surgery. J Minim Invasive Gynecol 2009, 16:63-67.

47. Grabe HJ, Frommer J, Ankerhold A, Ulrich C, Groger R, Franke GH, Barnow S, Freyberger HJ, Spitzer C: Alexithymia and outcome in psychotherapy. Psychother Psychosom 2008, 77:189-194.

48. Kooiman CG, Bolk JH, Rooijmans HG, Trijsburg RW: Alexithymia does not predict the persistence of medically unexplained physical symptoms. Psychosom Med 2004, 66:224-232.

49. Marchesi C, Bertoni S, Cantoni A, Maggini C: Is alexithymia a personality trait increasing the risk of depression? a prospective study evaluating alexithymia before, during and after a depressive episode. Psychol Med 2008, 38:1717-1722

50. Fortune DG, Richards HL, Griffiths CE, Main CJ: Targeting cognitivebehavior therapy to patients' implicit model of psoriasis: results from a patient preference controlled trial. Br J Clin Psychol 2004, 43:65-82.

51. De PC, Cero S, Dall'Aglio E, Salvatore $P$, Torre M, Maggini C: Psychopathological predictors of compliance and outcome in weightloss obesity treatment. Acta Biomed 2007, 78:22-28.

52. Mazzarella F, Alesii A, Dall'armi V, Rubino S, Ferri L: Alexithymia in respiratory rehabilitation. Disabil Rehabil 2010, 32:1116-1121.

53. Rufer M, Albrecht R, Zaum J, Schnyder U, Mueller-Pfeiffer C, Hand I, Schmidt O: Impact of alexithymia on treatment outcome: a naturalistic study of short-term cognitive-behavioral group therapy for panic disorder. Psychopathology 2010, 43:170-179

54. Aarela E, Saarijarvi S, Salminen JK, Toikka T: Alexithymic features do not predict compliance with psychotherapy in consultation-liaison patients. Gen Hosp Psychiatry 1997, 19:229-233.

55. Rufer M, Hand I, Braatz A, Alsleben H, Fricke S, Peter H: A prospective study of alexithymia in obsessive-compulsive patients treated with multimodal cognitive-behavioral therapy. Psychother Psychosom 2004, 73:101-106.

56. Schmidt $U$, Jiwany A, Treasure J: A controlled study of alexithymia in eating disorders. Compr Psychiatry 1993, 34:54-58.
57. van de Putte EM, Engelbert RH, Kuis W, Kimpen JL, Uiterwaal CS: Alexithymia in adolescents with chronic fatigue syndrome. J Psychosom Res 2007, 63:377-380.

58. Consoli SM, Rolhion S, Martin C, Ruel K, Cambazard F, Pellet J, Misery L: Low levels of emotional awareness predict a better response to dermatological treatment in patients with psoriasis. Dermatology 2006, 212:128-136.

59. Rufer M, Ziegler A, Alsleben H, Fricke S, Ortmann J, Bruckner E Hand I, Peter H: A prospective long-term follow-up study of alexithymia in obsessive-compulsive disorder. Compr Psychiatry 2006, 47:394-398.

60. Todarello O, Porcelli P, Grilletti F, Bellomo A: Is alexithymia related to negative symptoms of schizophrenia? a preliminary longitudinal study. Psychopathology 2005, 38:310-314.

61. Storch M, Keller F, Weber J, Spindler A, Milos G: Psychoeducation in affect regulation for patients with eating disorders: a randomized controlled feasibility study. Am J Psychother 2011, 65:81-93.

62. De Vries AM, Forni V, Voellinger R, Stiefel F: Alexithymia in cancer patients review of the literature. Psychother Psychosom 2012, 81(2):79-86.

63. Streiner DL, Norman GR: Health measurement scales. Oxford: Oxford University Press; 1994.

64. Marmot MG: Understanding social inequalities in health. Perspect Biol Med 2003, 46:59-23.

65. Marmot MG, Smith GD, Stansfeld S, Patel C, North F, Head J, White I, Brunner E, Feeney A: Health inequalities among British civil servants: the Whitehall II study. Lancet 1991, 337:1387-1393.

66. Marmot M: Status syndrome; how social standing affects our health and longevity. London: Bloomsbury Publishing; 2004.

67. Beresnevaite M: Exploring the benefits of group psychotherapy in reducing alexithymia in coronary heart disease patients: a preliminary study. Psychother Psychosom 2000, 69:117-122.

68. Melin E, Thulesius H, Persson B: Affect school for chronic benign pain patients showed improved alexithymia assessments with TAS-20. BioPsychoSocial Medicine 2010, 4:5

69. Fantini-Hauwel C, Dauvier B, Arciszewski T, Antoine P, Manouvrier S: Genetic testing for hereditary cancer: effects of alexithymia and coping strategies on variations in anxiety before and after result disclosure. Psychol Health 2011, 26:855-873.

70. Jorgensen MM, Zachariae R, Skytthe A, Kyvik K: Genetic and environmental factors in alexithymia: a population-based study of 8,785 Danish twin pairs. Psychother Psychosom 2007, 76:369-375.

71. Picardi A, Fagnani C, Gigantesco A, Toccaceli V, Lega I, Stazi MA: Genetic influences on alexithymia and their relationship with depressive symptoms. J Psychosom Res 2011, 71:256-263.

72. Taylor GJ, Bagby RM: Genetic contributions to alexithymia. Psychosom Med 2011, 73:633-635.

73. Valera EM, Berenbaum H: A twin study of alexithymia. Psychother Psychosom 2001, 70:239-246.

74. Walter NT, Montag C, Markett SA, Reuter M: Interaction effect of functional variants of the BDNF and DRD2/ANKK1 gene is associated with alexithymia in healthy human subjects. Psychosom Med 2011, 73:23-28.

75. De RA, Vanheule S: The relationship between perceived parenting, adult attachment style and alexithymia in alcoholic inpatients. Addict Behav 2006, 31:1265-1270.

76. Joukamaa M, Kokkonen P, Veijola J, Laksy K, Karvonen JT, Jokelainen J, Jarvelin MR: Social situation of expectant mothers and alexithymia 31 years later in their offspring: a prospective study. Psychosom Med 2003, 65:307-312.

77. Kokkonen P, Veijola J, Karvonen JT, Laksy K, Jokelainen J, Jarvelin MR, Joukamaa M: Ability to speak at the age of 1 year and alexithymia 30 years later. J Psychosom Res 2003, 54:491-495.

78. Freyberger $\mathrm{H}$ : Supportive psychotherapeutic techniques in primary and secondary alexithymia. Psychother Psychosom 1977, 28:337-342.

79. Taylor GJ: Recent develops in alexithymia theory and research. Can J Psychiatry 2000, 45:134-142.

80. Decety J, Moriguchi $Y$ : The empathic brain and its dysfunction in psychiatric populations: implications for intervention across different clinical conditions. BioPsychoSocial Medicine 2007, 1:22.

81. Bird G, Silani G, Brindley R, White S, Frith U, Singer T: Empathic brain responses in insula are modulated by levels of alexithymia but not autism. Brain 2010, 133:1515-1525. 
82. Fitzgerald M, Molyneux G: Overlap between alexithymia and Asperger's syndrome. Am J Psychiatry 2004, 161:2134-2135.

83. Berthoz S, Hill EL: The validity of using self-reports to assess emotion regulation abilities in adults with autism spectrum disorder. Eur Psychiatry 2005, 20:291-298.

84. Moriguchi Y, Maeda M, Igarashi T, Ishikawa T, Shoji M, Kubo C, et al: Age and gender effect on alexithymia in large, Japanese community and clinical samples: a cross-validation study of the Toronto alexithymia scale (TAS-20). BioPsychoSocial Medicine 2007, 1:7.

85. Igarashi T, Komaki G, Lane R, Moriguchi $Y$, Nishimura H, Arakawa $H$, et al: The reliability and validity of the Japanese version of the levels of emotional awareness scale (LEAS-J). BioPsychoSocial Medicine 2011, 5:2.

doi:10.1186/1751-0759-6-21

Cite this article as: Kojima: Alexithymia as a prognostic risk factor for health problems: a brief review of epidemiological studies.

BioPsychoSocial Medicine 2012 6:21.

\section{Submit your next manuscript to BioMed Central and take full advantage of:}

- Convenient online submission

- Thorough peer review

- No space constraints or color figure charges

- Immediate publication on acceptance

- Inclusion in PubMed, CAS, Scopus and Google Scholar

- Research which is freely available for redistribution 